\title{
A Portable Device for Intermittent Oxygen Supplementation during High-Intensity Exercise
}

\author{
P. Lindholm ${ }^{1,2 *}$, Å. Larsson ${ }^{2}$, O. Frånberg ${ }^{2,3}$, L. Gullstrand ${ }^{1,4}$ \\ ${ }^{1}$ Dept. Physiology and Pharmacology, Karolinska Institutet, Stockholm, Sweden \\ ${ }^{2}$ Oxelerate AB, Karlskrona, Sweden \\ ${ }^{3}$ Department of Mechanical Engineering, Blekinge Institute of Technology, Blekinge, Sweden \\ ${ }^{4}$ Elite Sports Centre, Bosön, Swedish Sports Confederation, Stockholm, Sweden \\ Email: * peter.lindholm@ki.se
}

How to cite this paper: Lindholm, P., Larsson, Å., Frånberg, O. and Gullstrand, L. (2017) A Portable Device for Intermittent Oxygen Supplementation during High-Intensity Exercise. J. Biomedical Science and Engineering, 10, 304-316.

https://doi.org/10.4236/jbise.2017.105023

Received: April 11, 2017

Accepted: May 28, 2017

Published: May 31, 2017

Copyright $\odot 2017$ by authors and Scientific Research Publishing Inc. This work is licensed under the Creative Commons Attribution International License (CC BY 4.0).

http://creativecommons.org/licenses/by/4.0/

\begin{abstract}
Introduction: Oxygen supplementation increases physical performance during strenuous work, as known for more than 100 years. There is no widespread use among athletes, which could be due to logistical challenges with gas supply when breathing over $200 \mathrm{~L} / \mathrm{min}$. We hypothesized that a positive effect could be reached with a moderate increase in alveolar $\mathrm{PO}_{2}$. If so, a technical solution here called "Oxelerator" could be constructed combining intermittent gas supply with oxygen concentrators running of electricity and a small bottle. Methods. This study describes the theoretical details regarding gas flow and consumption as well as a practical test of the Oxelerator when used during intense exercise by two athletes with high $\mathrm{VO}_{2}$ and work capacity. Results: The Oxelerator generates a peak gas flow of $32 \mathrm{~L} / \mathrm{min}$ dosed intermittently in 400 - 700 ms boluses adjusted to the inspiratory phase of breathing, mixing oxygen with surrounding air. Theoretical calculations show that 1 liter tank suffice for 20 - 40 minutes of high intensity exercise and hyperoxic $\mathrm{FEO}_{2}$ while breathing above $200 \mathrm{~L} / \mathrm{min}$. The first subject ran on a treadmill at a $\mathrm{VO}_{2}$ of $4.64 \mathrm{~L} / \mathrm{min}$, RER 0.94 . Then intermittent oxygen supplementation was initiated, and $\mathrm{FEO}_{2}$ reached $25.96 \%$ after 1 minute. The second subject rowed an ergometer at $330 \mathrm{~W} . \mathrm{VO}_{2}$ stabilized at $5.67 \mathrm{~L} / \mathrm{min}$, with RER 0.91 . After 1 minute of oxygen supplementation mixed expired $\mathrm{FEO}_{2}$ was $22.58 \%$ suggesting that inspired $\mathrm{FO}_{2}$ averaged $28-31 \%$. Conclusions: A portable technical solution is proposed that enable intermittent $\mathrm{O}_{2}$ supplementation enough to increase end-expiratory $\mathrm{FO}_{2}$ during intense workloads. This will enable hyperoxic exercise for athletes.
\end{abstract}

\section{Keywords}

Hyperoxia, Device, Training 


\section{Introduction}

Oxygen supplementation has been known to increase performance during strenuous work for more than 100 years [1]; it is thought that hyperoxia increases the oxygen content of the blood thus increasing $\mathrm{VO}_{2}$ [2]. Although Roger Bannister experimented with oxygen-enriched gas during training prior to running the first four-minute mile [3] as far back as the 1950s, since then there have been large variations regarding the effects of oxygen on physical performance in the literature. Many studies have examined the effect of inspired oxygen fractions varying from $0.26-1.00$, with most using 0.6 or above [4]-[9], for the acute effects of hyperoxia on maximal $\mathrm{VO}_{2}$, and also on peak workload and time to exhaustion. Others have investigated the effect of oxygen supplementation during exercise programs with evaluations of performance pre and post [5] [10] [11]. In general the results are positive but varying, and there are currently at least three theories regarding the mechanism of the effect on physical performance: increased $\mathrm{VO}_{2}$ [6], the effect on peripheral loading [8] and also the effect on the central nervous system [12] [13].

There are also studies showing beneficial effect of exercising with increased inspiratory oxygen fractions during a training regime [5], while it has also been shown that during hypoxic conditions at altitude, a modest oxygen supplementation would enable the "sleep high-train low" model [14] without the need of traveling to lower altitude. There are studies where athletes used oxygen in training during recovery between sessions [9] [15] and anecdotal reports of use in competition between sessions. However, there is no widespread, proven use of these types of techniques, despite their promising results in the literature.

The technical and logistical challenges in administering oxygen supplementation have to be considered as an explanation to this lack of use; an athlete ventilates 100 - 300 liter/minute (L/min) during intense exercise, so an estimate of the gas usage during a training session, dependent on session length could be around $5000 \mathrm{~L}$ of gas $(25 \mathrm{~min} \times 200 \mathrm{~L})$. That is equivalent to half of a $50 \mathrm{~L}$ tank of premixed gas (standard size). It could be further assumed that an athlete would consume $1 \mathrm{tank} /$ week if two training sessions were carried out on oxygen, a considerable amount. There are also logistical issues related to accessing medical grade oxygen (the quality needed for human breathing) as well as concerns regarding risk of fire when oxygen is used or stored indoors.

Recently, the medical technology market has developed oxygen concentrators capable of producing around 93\% oxygen (O93) continuously using household electricity, to be used by patients with increased oxygen requirements [16]. This technology is usually employed to provide a continuous flow of oxygen (93\%) of between $5-10 \mathrm{~L} / \mathrm{min}$, or in combination with a compressor to fill a small (portable) tank with gas. This technology would solve the challenge of oxygen production/delivery to the athlete or training facility, but if it used as manufactured, it would require 10 - 30 such units running simultaneously to supply an athlete during intense exercise.

Powers [6] showed that $26 \% \mathrm{FIO}_{2}$ was enough to increase $\mathrm{SaO}_{2}$ in highly trained 
athletes exhibiting exercise induced arterial hypoxemia EIAH [17]. If $26 \%$ is enough, could a moderate hyperoxia be enough to enhance an athlete's training performance? Also, bearing in mind that too great a hyperoxia $\left(\mathrm{PO}_{2}\right)$ might not be beneficial, as the exercise becomes too easy and so reduces the load needed to stimulate adaptation. We have recently shown that a moderate hyperoxia $\left(\mathrm{FIO}_{2}\right.$ $31 \%$ ) during moderate exercise (below lactate threshold) increased fat oxidation by $52 \%$ [18]. It also showed that maximal exercise performance increased by $2.4 \%$ in Watts, with a similar time to exhaustion at $80 \%$ of $\max$ [18]. Thus; if we hypothesize that a moderate hyperoxia would be enough to benefit the elite athlete and that the limited use of oxygen supplementation in sports training is due to the current logistical challenges, then the following hypothesis could be of use.

The Oxelerator is a device that detects breathing and heart rate, and then doses an appropriate bolus of gas for inspiration during intense exercise. In this way, mixing around $10-20 \mathrm{~L} / \mathrm{min}$ of oxygen into $100-200 \mathrm{~L}$ of room air will increase the mixed inspired gas to approximately $26 \%$ - 30\% oxygen (described in detail below). The aforementioned commercially available oxygen concentrators are capable of delivering an average flow of up to $10 \mathrm{~L} / \mathrm{min}$, with an instantaneous flow in excess of $30 \mathrm{~L} / \mathrm{min}$. A $1 \mathrm{~L}$ cylinder tank filled to 200 ATA contains $186 \mathrm{~L}$ of oxygen, if produced with O93 [16]. This is enough to produce hyperoxia for at least 20 minutes of intense interval training, and would more likely last for around 30 - 40 minute for an average athlete.

Thus, a portable device comprising a $1 \mathrm{~L}$ tank, a facemask and a dosing device called the Oxelerator [19] could be made available to deliver oxygen supplementation to an athlete. An oxygen concentrator could replenish the oxygen store either continuously (in stationary mode) or after the training session, refilling the tank overnight. This would make exercising while breathing hyperoxic gas possible in a practical manner for athletes where an extra 1 - 2 $\mathrm{kg}$ load is acceptable. This would include most skiers, cyclists, rowers, hockey players and many runners (in addition to exercise on treadmills or other stationary ergometers).

This study aims to describe the theoretical details of gas flow and consumption as well as a practical test of the Oxelerator when used during intense exercise by athletes with high $\mathrm{VO}_{2 \max }$ and work capacity. The aim was to show that a portable solution to hyperoxic exercise is technically feasible.

\section{Methods}

Ethics and subjects: The study was conducted in conformity with the principles of the Declaration of Helsinki and was approved by the Ethical Review Board of the Karolinska Institute. To test the performance of the Oxelerator device, two tests were executed in the laboratory. Two elite athletes (one runner and one rower) that often participate in regular physiological testing were recruited as participants for this study. The physiological capacity of these athletes was well established, as they were tested at least twice a year as a part of their training re- 
gimen. Thus prior knowledge was available regarding their likely performance and the workload necessary to produce a high $\mathrm{VO}_{2}$ that they could maintain without accumulating lactate. Both subjects gave their written informed consent before participation. The runner was tested for $\mathrm{VO}_{2} \max$ on an ergometer bike (Monark 828E, Monark Exercise AB, Varberg Sweden) within three weeks of this study and his results were $5.68 \mathrm{~L} / \mathrm{min}, 75.3 \mathrm{~mL} / \mathrm{kg} / \mathrm{min}$. The rower was tested six weeks prior to the study when his results were $6.70 \mathrm{~L} / \mathrm{min}, 63.7 \mathrm{~mL} /$ $\mathrm{kg} / \mathrm{min}$.

Technical description of the system (Figure 1(a) and Figure 1(b)):

A complete Oxelerate mobile system consists of the following sub units:

A) An mask made by Oxelerate (modified from an MSA gasmask) with dosage tube connections and dosage tubes connected (Figure 1(a)).

B) A Heart rate monitor and strap, currently using Polar ${ }^{\mathrm{Tm}}$ technology.

C) The Oxelerate Athlete Unit (Figure 1(a)).

The computerized unit controls and supervises the oxygen supplementation and includes a USB interface for optional communication, setup and charging.

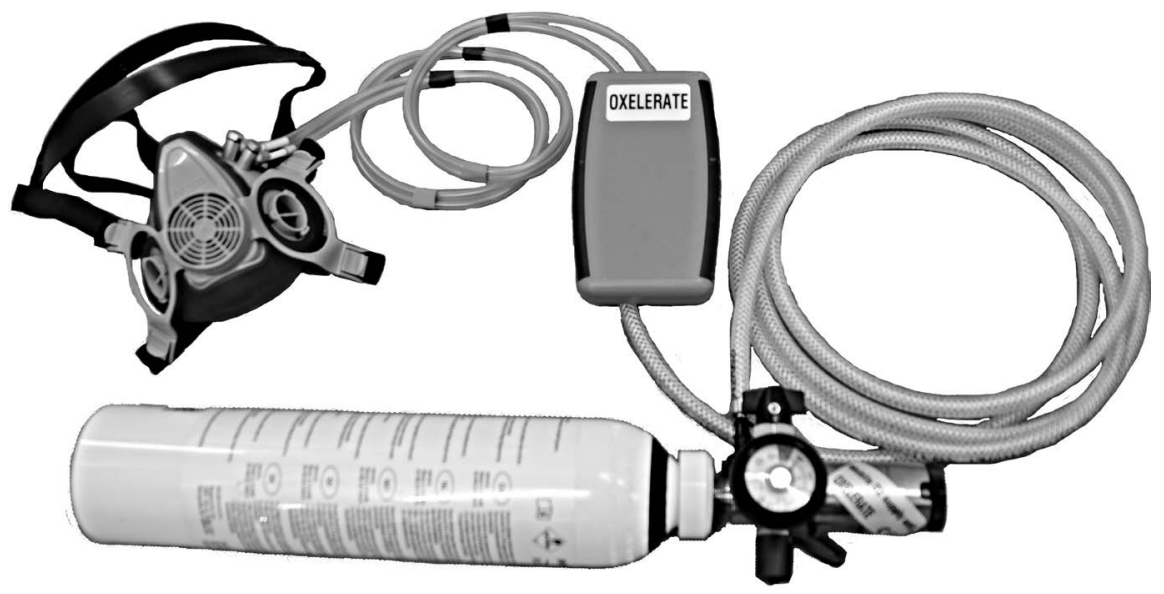

(a)

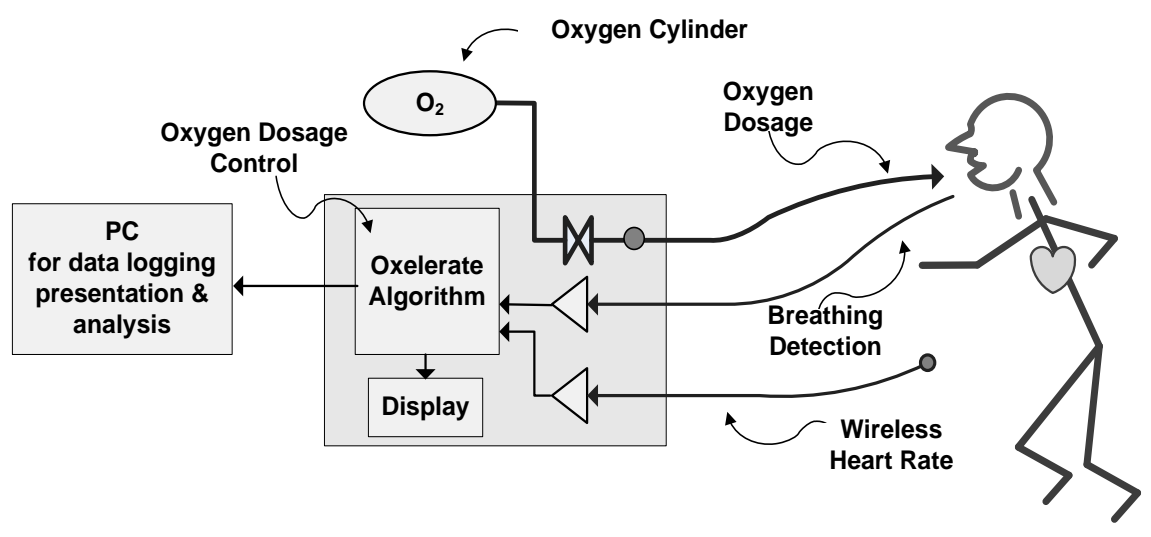

(b)

Figure 1. (a) The breathing mask, the oxelerator and the gas supply (tank); (b) Technical layout of the system with the oxelerator as the center square with algorithm, display and valves for control of gas flow. 
One length of tubing supplies the pressurized oxygen to the device and two narrower diameter tubes are used for respiratory sensing and dosing.

D) An oxygen tank of around $1 \mathrm{~L}$ volume, and 200 ATA pressure, with an integrated pressure regulator delivering $300 \mathrm{kPa}$ pressure absolute (2 BAR driving pressure) and a flow of $32 \mathrm{~L} / \mathrm{min}$ (Figure 1(a)).

E) A Backpack to house the Oxygen cylinder and Oxelerate Athlete Unit during exercise.

F) Oxelerate software running on a PC computer. The Software allows the setup and supervision of the system as well as data recording. The Oxelerator system can be used without the USB connection to the PC; during the tests the PC software was used to store test data, to monitor the test, and to control the oxygen supplementation.

G) The Oxygen supply subsystem based on an oxygen concentrator, for example the Philips EverFlo, and a tank filler, Phillips UltraFill. Another supplier also tested with this system is the Invacare Homefill system that includes both a concentrator and tank filler.

\subsection{Experimental Protocol}

Running: the participant $(75.4 \mathrm{~kg})$ ran on a high precision treadmill (Rodby Innovision, Sweden) at a $2 \%$ inclination at a speed of $15 \mathrm{~km} / \mathrm{h}$. After three minutes, data was collected for one minute as steady state values. Thereafter, boluses of $\mathrm{O}_{2}$ were added to each inspiration with $700 \mathrm{~ms}$ duration.

Rowing: The participant $(105.1 \mathrm{~kg}$ ) rowed an ergometer (Model D, Concept II, Inc. US) at $330 \mathrm{~W}$. After three minutes' work, data was collected for steadystate oxygen uptake for one minute. Thereafter boluses of $\mathrm{O}_{2}$ were added to each inspiration with $400 \mathrm{~ms}$ duration.

In order to enable analysis of exhaled gas, the subject wore a Combitox face mask (Dräger Safety AG, Lübeck, Germany) with the two hoses from the oxelerator inserted into a purpose-built adapter in front of the mouth, but upstream (closer to the mouth) of the flowmeter. The exhaled gas was analyzed with an Oxycon Pro, metabolic analyzer in the mixing chamber mode (CareFusion GmbH, Höchberg, Germany), validated by Foss \& Hallén, [20]. Measurements included ventilation $\left(\mathrm{V}_{\mathrm{E}}\right)$, expired oxygen fraction $\left(\mathrm{FEO}_{2}\right)$ and expired carbon dioxide fraction $\left(\mathrm{FECO}_{2}\right)$ with online calculation of $\mathrm{VO}_{2}, \mathrm{VCO}_{2}$, respiratory exchange ratio (RER), ventilation and breathing frequency.

The addition of oxygen boluses disabled this apparatus $\mathrm{VO}_{2}$ calculation, since its calculations are dependent on the subject inspiring room air, with only the exhaled gases measured. Therefore, two Douglas bags were collected during each test for mixing and analysis of expired $\mathrm{FO}_{2}$ and $\mathrm{FCO}_{2}$. The gases were analyzed by means of separate $\mathrm{O}_{2}$ and $\mathrm{CO}_{2}$ sensors (Mod. 17518A and 17515A, Vacumed, Ventura CA, US).

\subsection{Calculations}

Theoretical calculations were made using Microsoft Office Excel and standard 
equations for gas exchange and exercise physiology.

\section{Results}

\subsection{Theoretical Calculations for Estimated Gas Consumption and Alveolar $\mathrm{PO}_{2}$}

When activated, the Oxelerator delivers a flow of $32 \mathrm{~L} / \min$ (approx. $0.5 \mathrm{~L} / \mathrm{s}$ ). The bolus volume $\left(\mathrm{V}_{\text {bolus }}\right)$ delivered to the athlete will thus be controlled by the set opening time:

Equation $\mathrm{V}_{\text {bolus }}[\mathrm{L}]=$ duration of opening (the set bolus time) $[\mathrm{s}] * 32$ $[\mathrm{L} / \mathrm{min}] / 60[\mathrm{~s} / \mathrm{min}]$.

So for example at a bolus duration of $500 \mathrm{~ms}$, the volume of gas will be $500 / 1000 * 32 / 60 * 1000 \mathrm{ml}=267 \mathrm{~mL}$.

Thus the oxygen consumption (delivered volume) can be calculated using the breathing frequency and the bolus duration (Figure 2(a)) when it is set to a specific valve opening time at the beginning of a breath. Figure 2(a) could also be

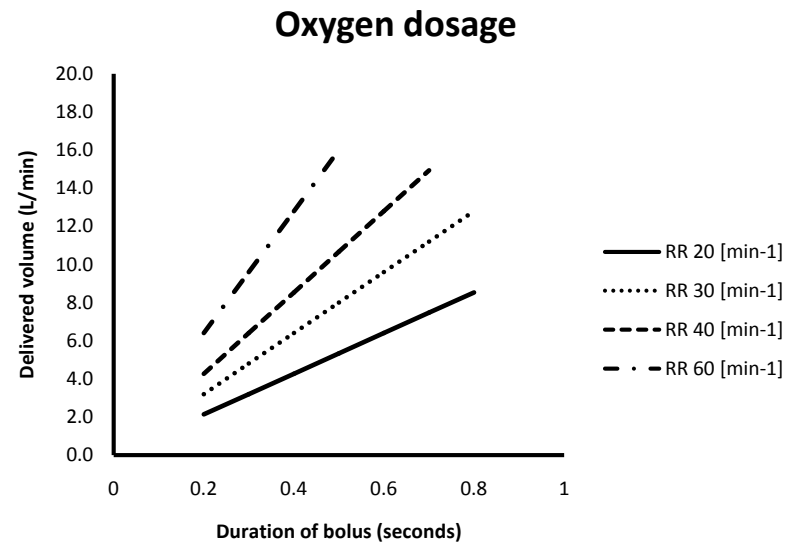

(a)

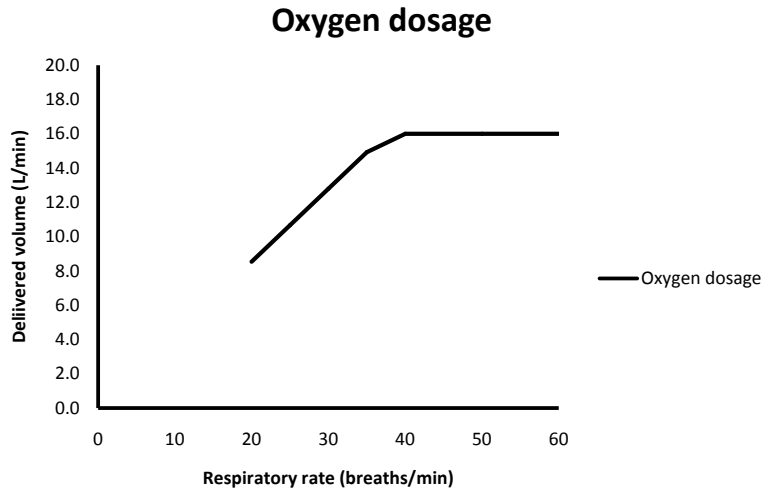

(b)

Figure 2. (a) Isopleths show respiratory rate (RR) in breaths/min and with the corresponding bolus duration on the $\mathrm{x}$-axis giving the delivered volume of oxygen in $\mathrm{L} / \mathrm{min}$; (b) Delivered volume of oxygen in $\mathrm{L} / \mathrm{min}$ as a function of respiratory rate in breaths/min, with a software setting to deliver gas during half the duration of a breathing cycle. With a maximum flow of $32 \mathrm{~L} / \mathrm{min}$ from the oxygen supply, a maximal value of $16 \mathrm{~L}$ will be delivered at or above a RR of 40 . 
used to determine gas consumption spending on settings and breathing frequency. It could also be used to roughly adjust settings or the oxygen store in order to make it last for the designated exercise session.

The duration of the bolus could also be adapted to the breathing frequency in order to vary the oxygen delivered according to breathing frequency, e.g. as "half the duration of the breath" where inspiration is considered to match expiration for duration (Figure 2(b)). If the valve opening duration is longer than inspiration, oxygen will be delivered during a pause or during expiration, i.e. wasting oxygen stored in the tank. This could be adjusted individually to the athletes' preferences or to the experimental setup in question.

Inspired $\mathrm{PO}_{2}$ will depend on tidal volume and the $\mathrm{V}_{\text {bolus }}$ of oxygen; Figure 3 show $\mathrm{FIO}_{2}$ as a function of tidal volume for three bolus volums, 100, 150 and 200 $\mathrm{ml}$. Estimations of alveolar $\mathrm{PO}_{2}$ could be made from expired end-tidal $\mathrm{PO}_{2}$, thus the fraction of expired $\mathrm{PO}_{2}$ would estimate the actual hyperoxia affecting the athlete. Figure 4(a) and Figure 4(b) show estimations made for dry gas without changing temperature or humidity. Work is considered aerobic with an RER of less than or equal to 1 .

\subsection{Laboratory Testing of the System}

The treadmill test: The steady-state reading gave values of- $\mathrm{VO}_{2} 4.64 \mathrm{~L} / \mathrm{min}$, RER 0.94 with a $\mathrm{V}_{\mathrm{E}}$ of $120.75 \mathrm{~L} / \mathrm{min}$ and a breathing frequency $(\mathrm{BF})$ of $38.3 . \mathrm{FEO}_{2}$ was $16.25 \%$ and $\mathrm{FECO}_{2}$ was $4.49 \%$. After another minute, the values were

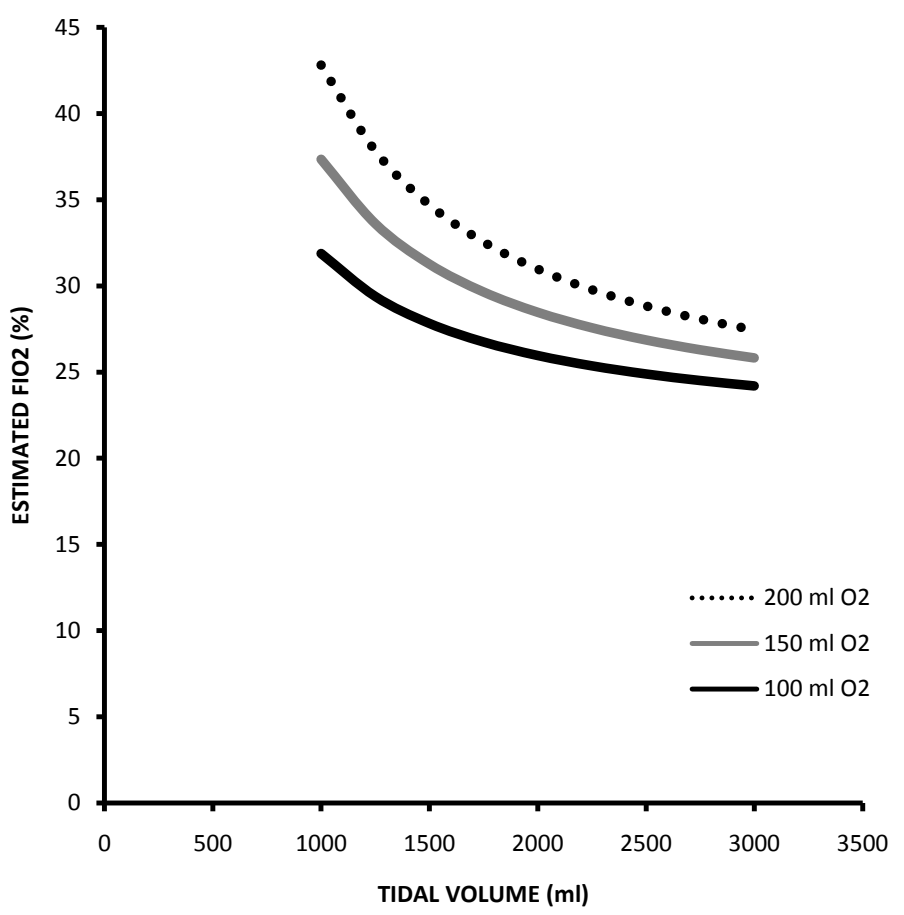

Figure 3. Estimated $\mathrm{FIO}_{2}$ depending on bolus volume from the Oxelerator and tidal volume. The dead space was set to $150 \mathrm{ml}$ and $\mathrm{FO}_{2}$ to $93 \%$ in the bolus gas. $\mathrm{FiO}_{2}=((\mathrm{Vt}-$ $\left.\left.\mathrm{V}_{\text {bolus }}\right) * 0.2093+\mathrm{V}_{\text {bolus }} * 0.93\right) / \mathrm{Vt}$ All calculations refer to dry gas volumes of equal temperature. 


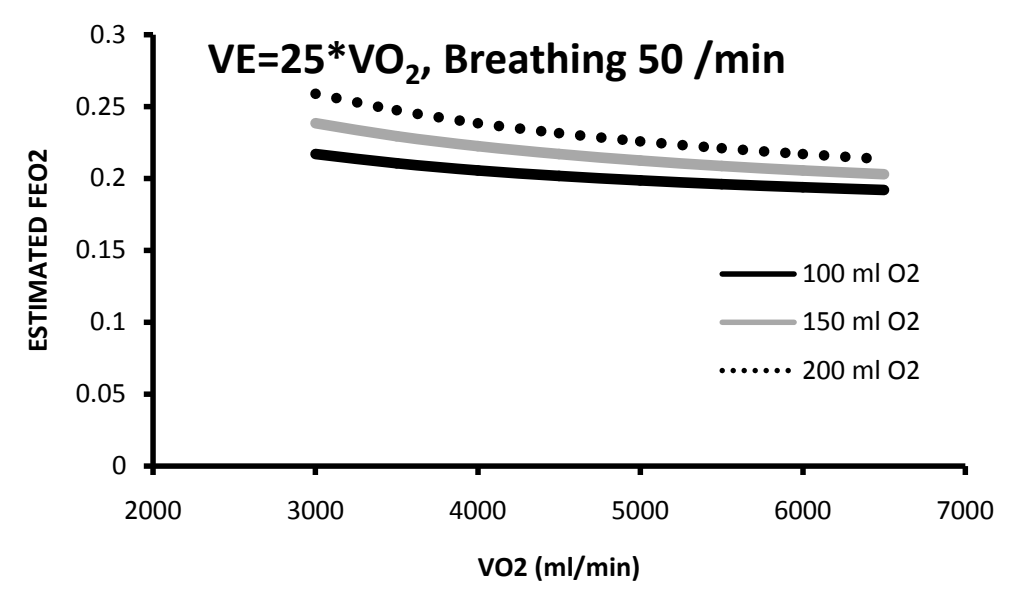

(a)

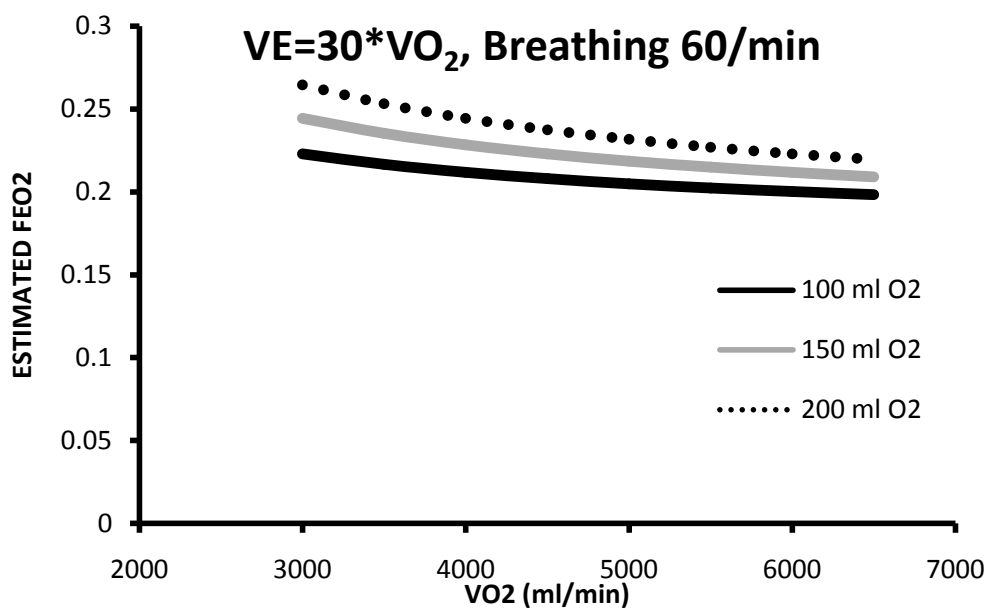

(b)

Figure 4. Estimated end tidal expired fraction of $\mathrm{O}_{2}$ (estimated with two different $\mathrm{V}_{\mathrm{E}} / \mathrm{VO}_{2}$ (a) 25 and (b) 30 and breathing frequencies of 50 and 60, respectively. Bolus dose of $93 \%$ oxygen of three different volumes 100 - $200 \mathrm{ml}$. Calculations made for aerobic work.

$\mathrm{VO}_{2} 4.75 \mathrm{~L} / \mathrm{min}$, RER 0.95, $\mathrm{V}_{\mathrm{E}} 121 \mathrm{~L} / \mathrm{min}, \mathrm{BF} 38.1, \mathrm{FEO}_{2} 16.15 \%$ and $\mathrm{FECO}_{2}$ $4.60 \%$. Oxygen supplementation was then initiated, which added $\mathrm{O}_{2}$ in boluses of $700 \mathrm{~ms}$ to each inspiration. After one minute the test started with collection of expired air into two Douglas bags for a period of one minute each. The value of $\mathrm{V}_{\mathrm{E}}$ after the first minute was 107.81 and $\mathrm{BF} 33.52$, with $\mathrm{FEO}_{2} 25.96 \%$ and $\mathrm{FECO}_{2}$ $4.93 \%$. The second minute $\mathrm{V}_{\mathrm{E}}$ was $111.76 \mathrm{l} / \mathrm{min}$, BF 34.8 and $\mathrm{FEO}_{2} 26.26 \%$ and $\mathrm{FECO}_{2}$ of $4.81 \%$. The total test duration was eight minutes.

In the second test, the subject rowed an ergometer at $330 \mathrm{~W}$. After three minutes $\mathrm{VO}_{2}$ stabilized at $5.67 \mathrm{~L} / \mathrm{min}$, with RER 0.91 and $\mathrm{V}_{\mathrm{E}} 139.3 \mathrm{~L} / \mathrm{min} . \mathrm{FEO}_{2}$ and $\mathrm{FECO}_{2}$ was $16.02 \%$ and $4.56 \%$ respectively and the $\mathrm{BF}$ was 43.9 breaths/min. After four minutes, steady state levels were considered, and data was averaged over the last minute: $\mathrm{VO}_{2}$ was $5.77 \mathrm{~L} / \mathrm{min}$, RER 0.91 and $\mathrm{V}_{\mathrm{E}} 142 \mathrm{l} / \mathrm{min} . \mathrm{FEO}_{2}$ was $16.03 \%$ and $\mathrm{FECO}_{2} 4.57 \%$. Breathing Frequency 46.5 breaths $/ \mathrm{min}$.

At this workload, the Oxelerator was turned on, which added $\mathrm{O}_{2}$ in boluses of $400 \mathrm{~ms}$ to each inspiration. After one minute, collection of gas in Douglas bags 
started for two separate minutes. BF was 45.4 for the first minute and 43.2 for the second. Mixed expired $\mathrm{FEO}_{2}$ was $22.58 \%$ and $\mathrm{FECO}_{2} 4.56 \%$ for the first minute and $22.54 \%$ and $4.66 \%$ for the second minute. VE was 132.27 for the first and 132.51 for the second. The machine was then turned off and after a minute, data was averaged for 30 seconds, which gave a $\mathrm{VO}_{2}$ of $5.73 \mathrm{l} / \mathrm{min}$ with an RER of 0.97 and an $\mathrm{FEO}_{2}$ of $16.01 \%$. Total test duration was $8 \mathrm{~min} 44 \mathrm{sec}$. Both tests were made at an ambient temperature of 20 degree Celsius, with $55 \%$ relative humidity and at $1002 \mathrm{hPa}$ pressure.

Data show that the portable Oxelerator system was able to supply boluses of oxygen enough to increase Alveolar $\mathrm{O}_{2}$ to a level that gave an expired $\mathrm{O}_{2}$ of 26 and $23 \%$ respectively, suggesting (expired $+5 \%$ ) that inspired $\mathrm{FO}_{2}$ averaged $28 \%$ $-31 \%$.

\section{Discussion}

The main focus of this paper was to calculate the possible performance of the Oxelerator device, as well as testing it during exercise with a substantial $\mathrm{VO}_{2}$ uptake in high workloads to evaluate whether it would deliver (as hypothesized) enough $\mathrm{O}_{2}$ to increase pulmonary $\mathrm{FO}_{2}$.

\subsection{Calculations}

Calculations show that a small increase in intrapulmonary $\mathrm{PO}_{2}(5-10 \mathrm{kPa})$ and a hyperoxic $\mathrm{FEO}_{2}$ could be achieved with a modest supplementation of oxygen, even in athletes with high ventilatory capacity and $\mathrm{VO}_{2}$ during exercise. This was achieved using an intermittent supplementation of $8-16 \mathrm{~L} / \mathrm{min}$ of $\mathrm{O}_{2}$ to inspired air that yielded this increase without using premixed gas tanks.

\subsection{Testing}

The setup was tested in connection with various sporting activities such as ergometer exercise on a bike, skating and roller skiing, as well as outdoor running or rowing with success according to the athletes' subjective experience. However, to collect a set of scientific quality data, we recruited two athletes with known high $\mathrm{VO}_{2}$ to be able to stress the system in an accurate testing protocol such as treadmill running and ergometer rowing. In these two tests only one setting was used for each subject, so the system was not individualized or optimized any more than to show that the Oxelerator was able to increase $\mathrm{PAO}_{2}$ enough to give an expired oxygen fraction above $21 \%$ during work with a $\mathrm{VO}_{2}$ of near 5 and 6 $\mathrm{L} / \mathrm{min}$. These two subjects (as well as others) had previously been tested on the system during development of the apparatus.

\subsection{Methodological Considerations}

Dead space: The oxygen supply could be extended further also if some basic respiratory physiology is considered; if the oxygen is supplemented to the inspired air only during the first part of the inspiration, this oxygen will mix with and result in an increased alveolar pressure of $\mathrm{O}_{2}$, while none of the oxygen will be 
left in the dead space thus using all the supplemented gas effectively.

Humidity issues: gas produced and stored in high-pressure tanks is dry to prevent corrosion and ice buildup. When breathing such gas, water has to be added by the mucus membranes in the airways to saturate the gas before reaching alveoli. In patient care, when supplemental oxygen is given at a flow of 5 - 15 $1 /$ min (resting) the gas is often pre-humidified to reduce humidity loss of the airway, usually by simply bubbling the gas through a water column. While a patient may breathe 5 - 10 liters of gas per minute, some elite athletes may reach 250 - $300 \mathrm{~L} /$ min during intense workloads.

In an exercising athlete, breathing from a humidity-free gas source will often cause discomfort due to the dry airway. If the oxygen supplementation is made by adding a relatively small bolus to ambient (i.e. already partially humidified) air, the effect on the average inspired humidity is less and the discomfort reduced or eliminated.

Fire hazard: using an oxygen tank indoors could increase the ambient oxygen fraction, which would increase the risk of fire in a poorly ventilated area. This risk is reduced significantly by the fact that the athlete will expire only about $25 \%$ Oxygen and the normal conditions for heavy exercise, which include ventilation to reduce $\mathrm{CO}_{2}$ in the room. This risk is reduced even further if the Oxelerator is connected to a concentrator that draws oxygen from the same room as it delivers it, i.e. the total $\mathrm{O}_{2}$ will not increase in the room.

If oxygen is to be used as a training aid for competitive sports, then the World Anti-Doping Agency (WADA) rules have to be considered. Of course, oxygen is not to be used during competition, but according to the latest WADA statement, supplemental oxygen is not considered an inappropriate training method. The WADA 2017 prohibited list clearly states that supplemental oxygen during training is excluded from this list:

M1. Manipulation of blood and blood components

The following are prohibited:

2: Artificially enhancing the uptake, transport or delivery of oxygen. Including, but not limited to: Perfluorochemicals; efaproxiral (RSR13) and modified haemoglobin products, e.g. haemoglobin-based blood substitutes and microencapsulated haemoglobin products, excluding supplemental oxygen by inhalation.

Actually, the last words "by inhalation" were added to the 2017 list to clarify a recent discussion on this topic.

The breathing of hyperoxic gas mixtures has possible negative effects on pulmonary function, as recognized from the fields of diving and hyperbaric medicine [21] where high oxygen partial pressures may be experienced for extended durations. In general, studies show that a $\mathrm{PO}_{2}$ of less than $50 \mathrm{kPa}\left(50 \% \mathrm{O}_{2}\right.$ at atmospheric pressure) does not damage the lung even when used for extended duration in e.g. diving [21] [22] [23]. There are other markers for oxidative stress that could be used to elucidate whether the proposed training method could increase oxidative stress: In a study on hematological and urinary markers for oxidative stress during high intensity exercise, it was shown that $\mathrm{FIO}_{2}$ of 0.6 
at moderate altitude did not produce higher values than inspiration of air or $\mathrm{FIO}_{2}$ of 0.26 [14]. At that altitude (1800-1900m) an $\mathrm{FIO}_{2}$ of 0.6 would equal a pressure at sea level corresponding to a $\mathrm{FIO}_{2}$ of 0.48 , which is higher than that of the presently suggested training method.

\subsection{Perspectives in Use and Practical Issues}

Hyperoxic training has almost only been performed in laboratory conditions due to the high volumes of gas needed. The proposed methodology would solve a practical problem, combining an oxygen concentrator and filler developed for medical purposes to a newly developed apparatus (the Oxelerator), which handles dosing volumes required for an exercising athlete, thus enabling he or she to exercise with oxygen wherever needed.

It is also possible to use this technology indoors together with a treadmill, rowing ergometer or cycle ergometer. In this case it would be preferable for the device to be connected to the exercise equipment with the hoses to the facemask suspended from the ceiling to the athlete. In most cases a suitable oxygen concentrator may be used continuously with such exercise, supplying the extra oxygen needed for the Oxelerator device (i.e. the tank may not be needed).

If we hypothesize that moderate supplemental oxygen is of benefit during intense work, and monitor breathing and heart rate, we can make a device with an algorithm supplementing small boluses of oxygen to inspiration during highintensity interval training, while keeping the gas consumption at $8-16$ liters/ minute. The delivery system may be set to deliver gas according to individual preferences in breathing and heart rate, to optimize the oxygen delivered, and make the oxygen store portable for a wide range of training methods.

\section{Acknowledgements}

Thomas Lindberg for assisting with physical tests on athletes. This technology is patent pending [19], and currently developed by a start-up company. The authors P.L., Å.L., and O.F. currently hold part of the patent rights, and the technology has been developed with support from the Karolinska Institutet and Kungliga Tekniska Högskolan (Royal School of Technology).

\section{References}

[1] Hill, L. and Flack, M. (1910) The Influence of Oxygen Inhalations on Muscular Work. The Journal of Physiology, 40, 347-372.

https://doi.org/10.1113/jphysiol.1910.sp001374

[2] Welch, H. (1982) Hyperoxia and Human Performance: A Brief Review. Medicine \& Science in Sports \& Exercise, 14, 253-262. https://doi.org/10.1249/00005768-198204000-00001

[3] Bannister, R. and Cunningham, D. (1954) The Effects on the Respiration and Performance during Exercise of Adding Oxygen to the Inspired Air. The Journal of Physiology, 125, 118-137. https://doi.org/10.1113/jphysiol.1954.sp005145

[4] Peltonen, J., Rantamaki, J., Niitymaki, S., Sweins, K., Viitasolo, J. and Rusko, H. (1995) Effects of Oxygen Fraction in Inspired Air on Rowing Performance. Medi- 
cine \& Science in Sports \& Exercise, 27, 573-579.

https://doi.org/10.1249/00005768-199504000-00016

[5] Perry, C.G., Reid, J., Perry, W. and Wilson, B.A. (2005) Effects of Hyperoxic Training on Performance and Cardiorespiratory Response to Exercise. Medicine \& Science in Sports \& Exercise, 37, 1175-1179. https://doi.org/10.1249/01.mss.0000169610.33318.54

[6] Powers, S., Lawler, J., Dempsey, J., Dodd, S. and Landry, G. (1989) Effects of Incomplete Pulmonary Gas Exchange on VO2max. Journal of Applied Physiology, 66, 2491-2495.

[7] Sperlich, B., Zinner, C., Krueger, M., Wegrzyk, J., Mester, J. and Holmberg, H.C. (2011) Ergogenic Effect of Hyperoxic Recovery in Elite Swimmers Performing High-Intensity Intervals. Scandinavian Journal of Medicine \& Science in Sports, 2, e421-e429. https://doi.org/10.1111/j.1600-0838.2011.01349.x

[8] Tucker, R., Kayser, B., Rae, E., Raunch, L., Bosch, A. and Noakes, T. (2007) Hyperoxia Improves $20 \mathrm{~km}$ Cycling Time Trial Performance by Increasing Muscle Activation Levels While Perceived Exertion Stays the Same. European Journal of Applied Physiology, 101, 771-781. https://doi.org/10.1007/s00421-007-0458-Z

[9] Wilson, G. and Welch, H. (1975) Effects of Hyperoxic Gas Mixtures on Exercise Tolerance in Man. Medicine \& Science in Sports \& Exercise, 7, 48-52. https://doi.org/10.1249/00005768-197500710-00010

[10] Kilding, A., Wood, M., Sequira, G. and Bonetti, D. (2012) Effect of Hyperoxic-Supplemented Interval Training on Endurance Performance in Trained Cyclists. International Journal of Sports Medicine, 33, 359-363. https://doi.org/10.1055/s-0031-1297999

[11] Perry, C.G., Talanian, J.L., Heigenhauser, G.J. and Spriet, L.L. (2007) The Effects of Training in Hyperoxia vs. Normoxia on Skeletal Muscle Enzyme Activities and Exercise Performance. Journal of Applied Physiology, 102, 1022-1027.

[12] Oussaidene, K., Prieur, F., Bougault, V., Borel, B., Matran, R. and Mucci, P. (2013) Cerebral Oxygenation during Hyperoxia-Induced Increase in Exercise Tolerance for Untrained Men. European Journal of Applied Physiology, 113, 2047-2056. https://doi.org/10.1007/s00421-013-2637-4

[13] Oussaidene, K., Prieur, F., Tagougui, S., Abaidia, A., Matran, R. and Mucci, P. (2015) Aerobic Fitness Influences Cerebral Oxygenation Response to Maximal Exercise in Healthy Subjects. Respiratory Physiology \& Neurobiology, 205, 53-60.

[14] Wilber, R.L., Holm, P.L., Morris, D.M., Dallam, G.M., Subudhi, A.W., Murray, D.M. and Callan, S.D. (2004) Effect of FIO2 on Oxidative Stress during Interval Training at Moderate Altitude. Medicine and Science in Sports and Exercise, 36, 1888-1894. https://doi.org/10.1249/01.MSS.0000145442.25016.DD

[15] Sperlich, B., Zinner, C., Kreuger, M., Wegrzyk, S.A. and Holmberg, H.C. (2012) Effects of Hyperoxia during Recovery from 5 x 30-s Bouts of Maximal-Intensity Exercise. Journal of Sports Sciences, 30, 851-858. https://doi.org/10.1080/02640414.2012.671531

[16] Prien, T., Meineke, I., Züchner, K., Boanță, A. and Rathgeber, J. (2014) Oxygen 93: A New Option for European Hospitals. British Journal of Anaesthesia, 113, 886887. https://doi.org/10.1093/bja/aeu359

[17] Dempsey, J.A. and Wagner, P.D. (1999) Exercise-Induced Arterial Hypoxemia. Journal of Applied Physiology, 87, 1997-2006.

[18] Manselin, T.A., Södergård, O., Larsen, F.J. and Lindholm, P. (2017) Aerobic Efficiency Is Associated with the Improvement in Maximal Power Output during Acute Hyperoxia. Physiological Reports, 5, e13119. https://doi.org/10.14814/phy2.13119 
[19] Larsson, Å., Frånberg, O., Frånberg, F. and Lindholm, P. (2014) PCT: WO-2012128704: A Device and Method for Supplying and Dosing Gas to a Breathing Person.

[20] Foss, Ø. and Hallén, J. (2005) Validity and Stability of a Computerized Metabolic System with Mixing Chamber. International Journal of Sports Medicine, 26, 569575. https://doi.org/10.1055/s-2004-821317

[21] Bove, A.A. (2014) Diving Medicine. American Journal of Respiratory and Critical Care Medicine, 189, 1479-1486. https://doi.org/10.1164/rccm.201309-1662CI

[22] Clark, J.M. and Lambertsen, C.J. (1971) Pulmonary Oxygen Toxicity: A Review. Pharmacological Reviews, 23, 37-133.

[23] Lumb, A.B. and Walton, L.J. (2012) Perioperative Oxygen Toxicity. Anesthesiology Clinics, 30, 591-605.

Submit or recommend next manuscript to SCIRP and we will provide best service for you:

Accepting pre-submission inquiries through Email, Facebook, LinkedIn, Twitter, etc. A wide selection of journals (inclusive of 9 subjects, more than 200 journals)

Providing 24-hour high-quality service

User-friendly online submission system

Fair and swift peer-review system

Efficient typesetting and proofreading procedure

Display of the result of downloads and visits, as well as the number of cited articles

Maximum dissemination of your research work

Submit your manuscript at: http://papersubmission.scirp.org/

Or contact jbise@scirp.org 